Sharif University of Technology
Scientia Iranica
Transactions E: Industrial Engineering
hCIENTIA

\title{
A fuzzy multi-objective multi-product supplier selection and order-allocation problem in supply chain under coverage and price considerations: An urban agricultural case study
}

\author{
A. Hajikhani ${ }^{a}$, M. Khalilzadeh ${ }^{a, *}$, and S.J. Sadjadi ${ }^{b}$ \\ a. Department of Industrial Engineering, Science and Research Branch, Islamic Azad University, Tehran, Iran. \\ b. Department of Industrial Engineering, Iran University of Science and Technology, Tehran, Iran.
}

Received 12 April 2016; received in revised form 22 October 2016; accepted 5 December 2016

\author{
KEYWORDS \\ Multi-objective \\ supplier selection \\ problem; \\ Coverage; \\ Fuzzy logic; \\ MOPSO; \\ NSGA-II.
}

\begin{abstract}
In this paper, a fuzzy multi-objective model is presented to select and allocate order to the suppliers in uncertain conditions, considering multi-period, multisource, and multi-product cases at two levels of a supply chain with pricing considerations. Objective functions considered in this study as the measures to evaluate the suppliers are the purchase, transportation, ordering costs, and timely delivering (or deference shipment quality, or wastages) which are amongst major quality aspects. Partial and general coverage of suppliers with respect to distance and finally suppliers' weights makes the amounts of product orders more realistic. Deference and coverage parameters in the model are considered as uncertain and random triangular fuzzy number. Since the proposed mathematical model is NP-hard, Multi-Objective Particle Swarm Optimization (MOPSO) algorithm is presented. To validate the performance of MOPSO, we applied non-dominated Sorting Genetic Algorithm (NSGA-II). Taguchi technique is executed to tune the parameters of both algorithms. A practical case study in an agricultural industry is shown to demonstrate that the proposed algorithm can be applied to the real-world problems. The results are analyzed using quantitative criteria, performing parametric, and non-parametric statistical analyses.

(C) 2018 Sharif University of Technology. All rights reserved.
\end{abstract}

\section{Introduction}

Supply Chain Management (SCM) involves suppliers, manufacturers, distribution centers, and retailers to ensure the efficient flow of raw materials, work-inprocess inventory, and finished products among facilities. Simchi et al. [1] provided SCM as a set of approaches applied to efficiently integrate suppliers,

\footnotetext{
*. Corresponding author.

E-mail address: mo.kzade@gmail.com (M. Khalilzadeh)
}

doi: $10.24200 /$ sci. 2017.4409 manufacturers, warehouses, and stores so that merchandise can be produced and distributed in the right quantities, to the right locations, and in the right time in order to minimize system-wide costs while satisfying service level requirements. Ghiani et al. [2] expressed that supply chain is a complex logistics system in which raw materials are converted into finished products and are distributed then to the final users. Besides, supplier selection is one of the most critical activities of purchasing management in a supply chain due to the crucial role of provider's performance in cost, quality, delivery, and service in achieving the objectives of a supply chain. 
Supplier selection is a Multiple-Criteria DecisionMaking (MCDM) problem affected by several conflicting different factors. Consequently, a purchasing manager must analyze the trade-off among the several criteria. MCDM techniques support the DecisionMakers (DMs) in evaluating a set of alternatives. Depending upon the purchasing situations, criteria have different importance levels, and there is a need to weight criteria [3]. Most parts of this research can be classified into two categories. SCM plays a significant role in competing firms of today's market, e.g., integrated supply chain can reduce total cost compared to the cost when each part decides independently. The SCM is the coordination between location, inventory, transportation, and production for a set, which consists of a network of facilities and distribution options, to reach the best mix of efficiency and responsiveness for the market being served [4].

In the literature, the goals in SCM models mostly include cost minimization, maximization of a type of utility function, minimization of late delivered items and rejected units, and so forth. In this paper, a nonlinear multi-objective programming model is developed whose objective functions consist of cost, delay, wastes, coverage from suppliers' side, and suppliers' weights. In this model, delay, coverage, and wastes from supplier's side are considered as fuzzy parameters and produced as random fuzzy. Finding the suppliers' weights through fuzzy TOPSIS using triangular fuzzy numbers and evaluating decision-makers are the novelties of such an objective function in this model. Consideration of coverage by providers for selecting and allocating order to suppliers is also another contribution of this study. In the problem at hand, vendor selection is performed according to the distance of customer from suppliers and considering the partial and complete coverage. To solve the model, a multi-objective meta-heuristic, called Multi-Objective Particle Swarm Optimization (MOPSO) algorithm, is proposed and compared with Non-dominated Sorting Genetic Algorithm (NSGAII). Tuning the parameters of the algorithm is also executed by the design of experiment and Taguchi method. Moreover, a practical case study in an urban agricultural irrigated lands of Abhar city in Middle East is shown to demonstrate that the proposed algorithm applies to the real-world problems. The rest of paper is organized as follows: Section 2 reviews some related works. Section 3 defines and mathematically formulate the multi-objective problems. Section 4 gives the explanations of both Pareto-based meta-heuristics in detail. Section 5 provides the process of tuning the parameters of the proposed algorithms by Taguchi approach. Section 6 presents the case study and compares the algorithms by graphical and statistical analyses. Section 7 presents discussion, conclusion, and remarks for future research.

\section{Related works}

Karasakal and Karasakal [5] suggested the partial coverage problem as a branch of maximum coverage problem. In their model, customer's demand coverage rate by every distribution center depends on the inverse of customer distance from that center. Liang [6] developed a fuzzy multi-objective model in a multi-product, multi-period case in two levels. In his model, he considered delivery cost and time as two objective functions and solved his model in a dynamic approach. Toraby and Hassini [7] developed a three-dimensional model in a multi-objective fuzzy case as multi-product with fixed demand. Their objective functions minimized the deviation variables for store constraint, deviation variable for future coverage constraint, and difference variables cost. Faith et al. [8] developed a multiitem system to select the suppliers using fuzzy and TOPSIS techniques in a group decision-making problem. Onot et al. [9] ranked the vendors utilizing fuzzy TOPSIS techniques and fuzzy ANP. They implemented their technique practically for communications system. Amid et al. [10] developed a linear multi-objective model whose objective functions and demand are indefinite and fuzzy; then, they solved their model using weighted sum technique. Kokangol and Susuz [11], by considering capacity, budget, and discount conditions into consideration, formulated and solved the supplier selection problem by developing a mixed model through mixing hierarchical analysis techniques, nonlinear mathematical programming model, and multiobjective programming model. Tsai and Wang [12] applied a mixed integer programming procedure to solve the problem and allocate order for a multi-source and multi-product case in the supply chain. Their objective functions included cost, minimization of the delay, and wastes from supplier's side. Two discount plans for all particles and exponential were applied to the problem, and three objectives, including the cost, number of returned product, and number of particles delivered with delay, were considered. Atakhan and Ali Fuat [13] provided a multi-objective model with fuzzy parameters and solved it through weighted maxmin technique. They obtained the weight of suppliers in their model through TOPSIS technique and utilized weighing method to integrate the objectives. Haleh and Hamidi [14] developed a fuzzy multi-objective model to allocate order to suppliers. In this model, hierarchical technique was used to obtain the suppliers' weights. They also set this weight as an objective function to select the vendors and solved this model using the maxmin method of the membership function. Liang [6] developed a fuzzy multi-objective model, whose parameters and objective functions are explained in the fuzzy environment. They converted their model into a single-objective function using max-min technique. 
Liao et al. [15] presented maximum distance constraint on covering the customers demand by distribution centers in the inventory location problem. In this model, if customers are located in the critical coverage distance, all their demands will be supplied; otherwise, the total demand will remain. Lin [16] developed a model for supplier selection under fuzzy conditions. He considered the multi-objective model to maximize suppliers weights as a single-objective function and solve the model alongside the functions of delivery cost and rate. His objective functions included cost, delay, and quality which were considered indefinite and fuzzy. Shaw et al. [17] developed an integer multiobjective model where their objective functions were purchase cost, delay, wasted or returned products, and environmental effect or greenhouse gasses. They converted objective functions into a single-objective function using weighed technique which obtained the suppliers' weights through fuzzy hierarchical method. Nazari-Shirkouhi et al. [18] presented a supplier selection problem for several cost levels and products with three objective functions including cost, delay, and wastes. Esfandiari and Seifbarghy [19] developed a multi-objective model consisting of minimizing the cost, delay, wastes and maximizing the supplier's weights. Their model was stochastic whose demand is achieved through Poisson probability function. Product cost from the provider's side has a linear discount. In this model, metric LP-technique was converted into a single-objective model. Arikan [20] developed an integer multi-objective model to select the suppliers where his model's objective functions are cost, ontime delivery, and delivered units percentage. Subsequently, he converted the objective functions into a single objective using max-min technique. Meena and Sarmah [21] developed a nonlinear single-objective model to select the supplier. This model is a mixed integer programming model. A customer confronts the cost discount and risk from the supplier's side to choose the provider. Eventually, this model was solved by genetic algorithm due to nonlinearity and complexity. Hajipour et al. [22,23] presented Paretobased meta-heuristic approaches, including NSGAII and non-dominated ranking genetic algorithm, to solve multi-objective facility location-allocation model. Patra and Kumar [24] proposed a bi-objective multiitem supplier selection problem to optimize objective functions: profit and risk. Orji and Wei [25] proposed a new modeling integrated approach to supplier behavior in the fuzzy environment with system dynamics simulation modeling technique leading to a more reliable decision support system. Rahiminezhad Galankashi et al. [26] presented an integrated balanced scorecardfuzzy analytic hierarchical process model to select the suppliers in the automotive industry. Amorim et al. [27] showed that a mixed adoption of informal and formal means of selection and control enhances supplier performance. Çebi and Otay [28] developed a two-stage fuzzy approach to supplier selection and order-allocation problem within discounts, lead time, capacity, and demand constraints. Niaki et al. [29] developed a multiple-buyer, multiple-vendor, multiproduct, and multi-constraint supply chain problem with stochastic demand and variable lead time: a harmony search algorithm. Jiuping et al. [30] developed an optimal model of a class of multi-objective supply chain networks under random fuzzy environment and its application to the industry of Chinese liquor and proposed a random fuzzy multi-objective mixedinteger non-linear programming model for the SCN design. Kamran and Moghaddam [31] proposed a fuzzy multi-objective model for supplier selection and orderallocation in reverse logistics systems under supply and demand uncertainty. Their modeling approach captures the inherent uncertainty in customers' demand, suppliers' capacity, and percentage of returned products as well as existence of conflicting objectives in reverse logistics systems. Mariya et al. [32] presented a modeling synergies in multi-criteria supplier selection and order allocation by an application to commodity trading. Yi Mei et al. [33] proposed an efficient meta-heuristics for the multi-objective timedependent orienteering problem and considered two meta-heuristic methods to propose a Multi-Objective Memetic Algorithm (MOMA) and a multi-objective ant colony system. Gulbin et al. [34] presented a multiobjective optimization of greenhouse gas emissions in highway construction projects. Matloub Hussain et al. [35] developed a framework for supply chain sustainability in service industry with confirmatory factor analysis and developed a comprehensive framework of sustainability measurement through successive stages of data collection, analysis, and refinement. Sadeghi et al. [36] optimized a multi-vendor multi-retailer vendor managed inventory problem. They found the order quantities along with the number of shipments received by retailers and suppliers, such that the total inventory cost of the chain is minimized. Since the problem is formulated into an integer nonlinear programming model, the meta-heuristic algorithm of Particle Swarm Optimization (PSO) is presented to find an approximate optimum solution to the problem. Jie Lu et al. [37], in a survey, systematically reviewed conventional multilevel decision-making techniques and cluster-related method developments into four main categories: bilevel decision-making (including multi-objective and multi-follower situations), tri-level decision-making, fuzzy multi-level decision-making, and the applications of these techniques in different domains. Stef Lemmens et al. [38] presented a review of integrated supply chain network design models. They provided an overview of how uncertainty is incorporated in the reviewed 
literature and can include disease epidemics, tender procurement, lead time variability and demand. Table 1 summarizes the related studies to clarify the main contribution of the present study in the formulated structure.

Supplier selection problem has become a critical objective of purchasing departments because of its importance in successful logistic and Supply Chain Management (SCM). In real-life situations, supplier selection parameters are uncertain and incomplete. In this respect, fuzzy sets theory is the best-developed approach to formulating these uncertainties. In this paper, we formulated the problem of multi-objective supplier selection problem in SCM with considering coverage from suppliers' side and supplier's weights. Consideration of coverage by suppliers for selecting and allocating the order to suppliers is also among the innovations of the present study. In this model, delay and coverage from supplier side are considered as fuzzy parameters and are produced as random fuzzy.

Table 1. The related studies in the problem at hand.

\begin{tabular}{|c|c|c|c|c|c|c|c|c|c|c|c|}
\hline & \multirow{3}{*}{$\begin{array}{c}\text { Deterministic } \\
\text { environment }\end{array}$} & \multicolumn{2}{|c|}{ Uncertainty } & \multirow{3}{*}{ 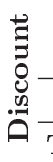 } & \multicolumn{5}{|c|}{$\begin{array}{l}\text { Supplier weight } \\
\text { objective function }\end{array}$} & \multirow{3}{*}{$\begin{array}{l}\text { Case } \\
\text { study }\end{array}$} & \multirow{3}{*}{$\begin{array}{c}\text { Multi- } \\
\text { objective }\end{array}$} \\
\hline & & $\overbrace{0}^{\infty}$ & & & Crisp & & & Fuzzy & & & \\
\hline & & $\circlearrowright$ Fuzzy & Probabilistic & & TOPSIS & AHP & ANP & TOPSIS & AHP & & \\
\hline $\begin{array}{c}\text { Karasakal and } \\
\text { Karasakal (2004) }\end{array}$ & $\sqrt{ }$ & $\sqrt{ }$ & & & & & & & & & \\
\hline $\begin{array}{c}\text { Onot et al. } \\
(2009)\end{array}$ & & $\sqrt{ }$ & & & & & $\sqrt{ }$ & & & $\sqrt{ }$ & \\
\hline $\begin{array}{l}\text { Amid et al. } \\
\text { (2009) }\end{array}$ & & $\sqrt{ }$ & & & & & & & & & $\sqrt{ }$ \\
\hline $\begin{array}{l}\text { Kokangol and } \\
\text { Susuz (2009) }\end{array}$ & $\sqrt{ }$ & & & $\sqrt{ }$ & & $\sqrt{ }$ & & & & $\sqrt{ }$ & $\sqrt{ }$ \\
\hline $\begin{array}{c}\text { Fatih et al. } \\
\text { (2009) }\end{array}$ & & $\sqrt{ }$ & & & $\sqrt{ }$ & & & & & & \\
\hline $\begin{array}{l}\text { Wang and } \\
\text { Yang (2009) }\end{array}$ & & $\sqrt{ }$ & & $\checkmark$ & & & & & & & \\
\hline $\begin{array}{l}\text { Mohammad } \\
\text { Ebrahim } \\
\text { et al. }(2009)\end{array}$ & $\sqrt{ }$ & & & $\sqrt{ }$ & & & & & & & \\
\hline $\begin{array}{c}\text { Tsai \& } \\
\text { Wang (2010) }\end{array}$ & $\sqrt{ }$ & & & $\sqrt{ }$ & & & & & & & $\sqrt{ }$ \\
\hline $\begin{array}{c}\text { Niaki et al. } \\
(2011)\end{array}$ & & & $\sqrt{ }$ & & & & & & & & \\
\hline $\begin{array}{c}\text { Yang et al. } \\
(2011)\end{array}$ & $\checkmark$ & & & & & & & & & & \\
\hline $\begin{array}{l}\text { Zhong et al. } \\
\quad(2011)\end{array}$ & $\sqrt{ }$ & & & $\checkmark$ & & & & & & & \\
\hline $\begin{array}{c}\text { Atakhan \& } \\
\text { Ali Fuat } \\
\text { (2011) }\end{array}$ & & $\sqrt{ }$ & & & $\sqrt{ }$ & & & & & & $\sqrt{ }$ \\
\hline $\begin{array}{l}\text { Haleh \& } \\
\text { Hamidi (2011) }\end{array}$ & & $\sqrt{ }$ & & & & $\sqrt{ }$ & & & & & $\sqrt{ }$ \\
\hline
\end{tabular}


Table 1. The related studies in the problem at hand (continued).

\begin{tabular}{|c|c|c|c|c|c|c|c|c|c|c|c|c|}
\hline & \multirow{3}{*}{$\begin{array}{l}\text { Deterministic } \\
\text { environment }\end{array}$} & \multirow{3}{*}{$\begin{array}{l}0 \\
80 \\
5 \\
0 \\
0 \\
0 \\
0 \\
0\end{array}$} & \multicolumn{2}{|c|}{ Uncertainty } & \multirow{3}{*}{ 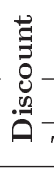 } & \multicolumn{5}{|c|}{$\begin{array}{c}\text { Supplier weight } \\
\text { objective function }\end{array}$} & \multirow{3}{*}{$\begin{array}{c}\text { Case } \\
\text { study }\end{array}$} & \multirow{3}{*}{$\begin{array}{c}\text { Multi- } \\
\text { objective }\end{array}$} \\
\hline & & & \multirow{2}{*}{ Fuzzy } & \multirow[b]{2}{*}{ Probabilistic } & & \multicolumn{2}{|c|}{ Crisp } & \multicolumn{3}{|c|}{ Fuzzy } & & \\
\hline & & & & & & TOPSIS & AHP & ANP & TOPSIS & AHP & & \\
\hline $\begin{array}{l}\text { Liao et al. } \\
\qquad(2011)\end{array}$ & $\sqrt{ }$ & $\sqrt{ }$ & $\sqrt{ }$ & & & & & & & & & $\sqrt{ }$ \\
\hline $\begin{array}{l}\text { Fu Liang } \\
(2011)\end{array}$ & & & $\sqrt{ }$ & & & & & & & & $\sqrt{ }$ & $\sqrt{ }$ \\
\hline Lin $(2012)$ & & & $\sqrt{ }$ & & & & & $\sqrt{ }$ & & & & $\sqrt{ }$ \\
\hline $\begin{array}{l}\text { Shaw et al. } \\
\qquad(2012)\end{array}$ & & & $\sqrt{ }$ & & & & & & & $\sqrt{ }$ & $\sqrt{ }$ & $\sqrt{ }$ \\
\hline $\begin{array}{c}\text { Esfandiari and } \\
\text { Seyfbarghy (2013) }\end{array}$ & & & & $\sqrt{ }$ & $\sqrt{ }$ & & $\sqrt{ }$ & & & & & $\sqrt{ }$ \\
\hline $\begin{array}{c}\text { Meena and } \\
\text { Sarmah (2013) }\end{array}$ & & & & & $\sqrt{ }$ & & & & & & & \\
\hline $\begin{array}{c}\text { Min and } \\
\text { Goh (2014) }\end{array}$ & & & & & & & & & & & & \\
\hline $\begin{array}{c}\text { Patra and } \\
\text { Kumar (2015) }\end{array}$ & & & $\sqrt{ }$ & & & & & & & & & \\
\hline $\begin{array}{c}\text { Orji and } \\
\text { Wei }(2015)\end{array}$ & & & $\sqrt{ }$ & & & & & & & & & \\
\hline $\begin{array}{c}\text { Rahiminezhad } \\
\text { Galankashi } \\
\text { et al. (2016) }\end{array}$ & $\sqrt{ }$ & & & & & & & & & $\sqrt{ }$ & & \\
\hline $\begin{array}{l}\text { Amorim et al. } \\
\qquad(2016)\end{array}$ & & & & $\sqrt{ }$ & & & & & & & & \\
\hline $\begin{array}{c}\text { Çebi and Otay } \\
(2016)\end{array}$ & & & $\sqrt{ }$ & & $\sqrt{ }$ & & & & & & & \\
\hline This paper & & $\sqrt{ }$ & $\sqrt{ }$ & $\sqrt{ }$ & $\sqrt{ }$ & & & & $\sqrt{ }$ & & $\sqrt{ }$ & $\sqrt{ }$ \\
\hline
\end{tabular}

A practical case study in the agricultural industry is shown in order to demonstrate that the proposed algorithm applies to the real-world problems. A parameter-tuned Pareto-based algorithm is presented to tackle the problem in hand.

\section{Problem formulation}

Supplier selection problem is an MCDM problem in which each criterion has specific importance. There are various criteria to select and allocate order to suppliers. In this paper, we presented a supply selection problem in SCM in fuzzy environment and the objective of coverage maximization. Therefore, before explaining the mathematical formulation of the problem, the main features of our proposed problem are described in the following subsections.

\subsection{Maximal Covering Location Problem $(M C L P)$}

Maximal Covering Location Problem (MCLP) maximizes the number of demand points covered within a specified critical distance or time by a fixed number of facilities. It does not require that all demand points be covered [5]. Our approach can be applied to location problems where the service is at the top level 


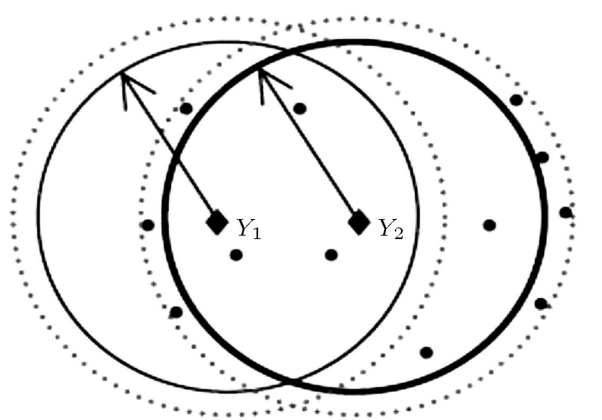

Figure 1. A possible situation for an MCLP.

(i.e., fully covered) within a minimum critical distance, decays with distance (i.e., partially covered) beyond the minimum critical distance until the maximum critical distance, and drops to no-service level beyond this range. We believe that modeling such problems by allowing partial coverage (partial service level) is more reasonable than using the classical MCLP approach. For instance, it may be important to model the service facility location problems, military logistics problems, and military targeting problems in the presence of partial coverage. Figure 1 represents the possible solutions to MCLP.

Suppose that there are two potential facilities, and we follow to choose one with the maximal covering. The solid line shows the minimum critical distance and dotted line shows the maximum critical distance. Location $Y_{1}$ can cover six demand points, and position $Y_{2}$ can cover five demand points within the full coverage range. Thus, a standard MCLP solution chooses location $Y_{1}$ as the location of maximal coverage. If we apply the partial coverage idea, we may select location $Y_{2}$ instead of location $Y_{1}$, because location $Y_{2}$ covers five demand points entirely and additional seven demand points partially, while location $Y_{1}$ covers only six demand points thoroughly [5]. Coverage is calculated as follows:

$$
\begin{gathered}
\mu_{\tilde{a}}(x)= \begin{cases}1 & w_{i j} \leq S_{j} \\
L\left(w_{i j}\right) & S_{j}<w_{i j}<R_{j} \\
0 & w_{i j} \geq R_{j}\end{cases} \\
L\left(w_{i j}\right)=\frac{R_{j} w_{i j}}{R_{j}-S_{j}} \quad 0<L<1,
\end{gathered}
$$

where $S_{j}$ and $R_{j}$ are maximum distances for complete and partial coverage by supplier $j$, respectively.

\subsection{Indices and parameters}

$\begin{array}{ll}i & \text { Index of customers }(i=1,2, \ldots, I) \\ j & \text { Index of suppliers }(j=1,2, \ldots, J) \\ k & \text { Index of products }(k=1,2, \ldots, K) \\ t & \text { Index of periods }(t=1,2, \ldots, T) \\ r & \text { Index of discount level }(r=1,2, \ldots, R) .\end{array}$

$P_{i j k t} \quad$ Unitary purchasing cost of product $k$ by customer $i$ in period $t$ from supplier $j$

$\tilde{t}_{j k t} \quad$ Delay rate of product $k$ in period $t$ by supplier $j$

$\tilde{b}_{i j} \quad$ Coverage rate of center $j$ for customer $i$

$D_{i k t} \quad$ Demand of customer $i$ for product $k$ in period $t$

$\tilde{W}_{j} \quad$ The weight of supplier $j$

$f_{j k t} \quad$ Fixed cost of ordering for supplier $j$ in period $t$ for product $k$

$P_{k t j r}^{\prime} \quad$ Price of each unit product $k$ offered by supplier $j$ in period $t$ in discount level $r$

$C_{j k t} \quad$ Capacity of supplier $j$ for product $k$ in period $t$

$n_{i k t} \quad$ Maximum number of supplier for customer $i$ and product $k$ in period $t$

$T_{i j} \quad$ Maximum price of receipt delay for purchased goods by buyer $i$ from supplier $j$

$v_{i j k} \quad$ Cost of shipment per each unit product $k$ from supplier $j$ to customer $i$ in distance unit

$w_{i j} \quad$ Distance of supplier $j$ to customer $i$

$H_{j} \quad$ Minimum number of ordering for each supplier $j$

$O_{i t} \quad$ Maximum budget of customer $i$ in period $t$

\subsection{Decision variables}

$x_{i j k t} \quad$ Purchasing quantity of product $k$ by buyer $i$ from supplier $j$ in period $t$

$y_{i j k t} \quad$ One if customer $i$ buys product $k$ in period $t$ from supplier $j$; zero, otherwise.

\subsection{Assumptions}

In order to explain the problem, the assumptions are given as follows:

- Demand is deterministic and depends on supplier selection and order-allocation factors;

- Shortage is not permissible;

- Discount is universal and has a sign function;

- All suppliers can produce all products;

- The supply chain is a multi-product, multi-buyer and two-echelon structure.

\subsection{The proposed mathematical modeling}

- The first objective: Cost function. The cost function is composed of three parts including 
purchase cost, shipment cost, and fixed cost of ordering. In the first part, the price of each product is offered by the suppliers where this price has the sign function discount. Customers in each period order their products to the suppliers based on the suggested price. The second part of the objective function is the shipment cost which is calculated based on the customer distance from the supplier; so, ordering amount of the supplier and selection of nearer supplier is performed. In the third part, the fixed cost of ordering for each product of suppliers is offered based on which selection of a supplier with lower cost is considered. Price is considered as a decision variable. According to the suggested price, demand is provided:

$$
\begin{aligned}
\operatorname{Min} Z_{1}= & \sum_{i, j, k, t} P_{i j k t} x_{i j k t} \\
& +\sum_{i, j, k, t} w_{i j} v_{i j k} x_{i j k t} y_{i j k t}+\sum_{i, j, k, t} f_{j k t} y_{i j k t} .
\end{aligned}
$$

- The second objective: Delay function. The second objective function is presented to minimize the delay from supplier's side. In this objective function, according to the delay for each product, amount of ordering for each product to the suppliers is defined. On the other hand, since the delays by suppliers have uncertainty, to reach the reality, parameter of delays is considered as random triangular fuzzy numbers:

$$
\operatorname{Min} Z_{2}=\sum_{i, j, k, t} \tilde{t}_{j k t} x_{i j k t} .
$$

- The third objective: Maximal covering function. The third objective function is maximizing the coverage of customer's suppliers. In this objective function, according to the distance of clients from suppliers and partial and complete coverage of suppliers, percentage of coverage of each supplier for each customer is calculated where supplier selection is performed according to the demand coverage rate for each customer by each supplier. The parameter of coverage rates is considered as random triangular fuzzy numbers:

$$
\operatorname{Max} Z_{3}=\sum_{i, j, k, t} \tilde{b}_{i j} D_{i k t} y_{i j k t}
$$

- The fourth objective: Suppliers weight function. In this objective function, product ordering rate is defined according to the supplier's weights. To make supplier's evaluation more realistic and select the best suppliers, supplier's weight is obtained through fuzzy TOPSIS technique:

$$
\operatorname{Max} Z_{4}=\sum_{i, j, k, t} \tilde{W}_{j} x_{i j k t} .
$$

The final proposed mathematical model for multiproduct supplier selection and allocating order under signal function discount and maximal cover policy is formulated as follows:

$$
\begin{aligned}
\operatorname{Min} Z_{1}= & \sum_{i, j, k, t} P_{i j k t} x_{i j k t}+\sum_{i, j, k, t} w_{i j} v_{i j k} x_{i j k t} y_{i j k t} \\
& +\sum_{i, j, k, t} f_{j k t} y_{i j k t},
\end{aligned}
$$

$$
\begin{aligned}
& \operatorname{Min} Z_{2}=\sum_{i, j, k, t} \tilde{t}_{j k t} x_{i j k t}, \\
& \operatorname{Max} Z_{3}=\sum_{i, j, k, t} \tilde{b}_{i j} D_{i k t} y_{i j k t}, \\
& \operatorname{Max} Z_{4}=\sum_{i, j, k, t} \tilde{W}_{j} x_{i j k t} .
\end{aligned}
$$

Subject to:

$$
\begin{aligned}
& \sum_{j} x_{i j k t} \geq D_{i k t} ; \quad \forall i, k, t \\
& \sum_{j} x_{i j k t} \leq \sum_{j} \tilde{b}_{i j} D_{i k t} ; \quad \forall i, k, t \\
& \sum_{j} x_{i j k t} \leq c_{j k t} ; \quad \forall i, k, t \\
& 1 \leq \sum_{j} y_{i j k t} \leq n_{i k t} ; \quad \forall i, k, t, \\
& \tilde{t}_{j k t} x_{i j k t} \leq T_{i j} \tilde{b}_{i j} D_{i k t} ; \quad \forall i, j, k, t, \\
& a_{(i, j, k, t, r)}=\operatorname{sign}\left[\operatorname{sign}\left(x_{i j k t}-q_{j k t, r-1}\right)\right. \\
& \left.\quad+\operatorname{sign}\left(q_{j k t r}-x_{i j k t}\right)\right] ; \quad \forall i, j, k, t, r \\
& \sum_{j, k} y_{i j k t}\left[P_{i j k t}+\left(w_{i j} v_{i j k}\right)+f_{j k t}\right] \leq O_{i t} ; \\
& x_{i j k t} y_{i j k t} \geq H_{j} ; \quad \forall i, j, k, t, \\
& x_{i j k t} \leq M . y_{i j k t} ; \quad \forall i, j, k, t, \\
& \quad \forall i, j, k, t,
\end{aligned}
$$

Constraints (7) represent the fact that ordering 
rate of each customer for each product in each period from suppliers must be greater than or equal to the customer demand for that product in the desired period to avoid any shortage. Constraints (8) indicate that the ordering rate must be less than or equal to the coverage rate of supplier for the desired customer. This constraint is provided for objective function of coverage, and the supplier with more coverage is selected. On the other hand, this constraint defines the ordering rate after selecting the supplier. Constraints (9) show supplier's capacity constraint to explain that ordering rate of each product by the customers in each period must be according to the capacity of each supplier. Constraints (10) illustrate the fact that amount of applying the suppliers to each product in each period by the customer must be according to the number defined by the managers. Also, each customer in each period must purchase the product at least from one supplier. Constraints (11) assure that delays reception rate of each product by each customer in each period for each supplier must be defined by decision-makers. Constraints (12) and (13) show that price of each product offered by the suppliers has a discount of sign function type in which $a(i, j, k, t, r)$ are positive variables, and their summation is one. When $x$ is positive in sign function, one is returned; if $x$ is zero, 0 is returned; when $x$ is negative, -1 is returned. Therefore, $a(i, j, k, t, r)$ corresponding to each discount rate are activated according to the order rate; $x$ as well as other ranges are zero and become inactivated. In this way, price of each product is found. Constraint (14) represent the amount of fund belonging to each customer in each period, where expenditure rate in supply chain must be equal to this fund. Constraints (15) ensure that order rate for each customer must be at least equal to the amount defined by the supplier. Otherwise, if the order rate to the supplier is lower than the permitted number, it will not be performed, and purchase from that supplier is not applicable. Constraints (15) ensure that by opening each relation, transportation and material handling can be provided. Constraints (17) and (18) give the range of decision variables.

\subsection{Handling random fuzzy numbers}

In this study, as mentioned, some parameters are considered as random triangular fuzzy numbers where the way of constructing these numbers should be illustrated. Firstly, using uniform distribution, 100 numbers for each parameter matrix solution are generated based on the desired parameter's range. Then, through minimizing the numbers of the first triangular fuzzy number, from mean numbers of the middle number and through the maximization of the numbers, the final fuzzy number is found. Finally, utilizing the mean distribution , $\beta$, triangular fuzzy numbers are converted into crisp. This is done for all the results of the desired parameter matrix. Moreover, $B$ mean distribution formulation is applied for the defuzzification of random triangular fuzzy numbers in the objective functions of delays, coverage rates, and weight [39-41]:

$$
\tilde{B}=\left(\mathbf{B}^{\mathrm{p}}, \mathbf{B m}, \mathbf{B}^{0}\right), \quad B=\frac{\mathbf{B}^{\mathbf{p}}+4 \mathbf{B} \mathbf{m}+\mathbf{B}^{0}}{6} .
$$

\section{Two Pareto-based meta-heuristics algorithms}

Since the problem of this study belongs to the NP-hard class ones, to solve the proposed mathematical model, two Pareto-based meta-heuristic algorithms, called Non-dominate Sorting Genetic Algorithm (NSGAII) and Multi-Objective Particle Swarm Optimization (MOPSO), are applied.

\subsection{NSGA-II}

NSGA (or NSGA-I) has had some drawbacks such as computational complexity, non-elitist operation, and the necessity of a sharing parameter which can be entirely preventable. Hence, NSGA-II was proposed by Deb et al. [42] as a class of multi-objective evolutionary algorithms consisting of a fast and capable sorting procedure together with an elitism operation. The Pseudo-code of NSGA-II is illustrated in Figure 2. The main idea of this algorithm is to reproduce a new population from an initial population and distribute these two populations over the entire Pareto optimal set(s). Meanwhile, in order to find the best possible solutions and acquire the Pareto set(s), we need to prioritize solutions by assigning a rank to each solution. Therefore, a process, called non-domination sorting, is applied by Figure 3 . Note that there are two main parameters in this process: the number of solutions dominating a specific solution $\left(N_{p}\right)$ and a set of solutions prevailed by the specific solution $\left(S_{p}\right)$.

In Figure 3, two main points need to be taken into account: (I) This sorting process is an iterative procedure which labels each solution with an unnecessarily unique level/rank. In other words, by this process, it might be possible to have several solutions having the same level/rank; and (II) For a minimization problem, the same as our problem, the best level has rank 1, and the second level has rank 2, and so on. Now, after applying this approach, each solution recognizes its rank as a fitness evaluation, according to Deb et al. [42].

\subsubsection{Solution representation}

The solution structure of the problem (chromosome) consists of two parts. The first part of chromosome indicates the order rate for each product by the customer in each period. The second part of chromosome also is considered as a binary variable 
Step 1: Randomly create an initial population Ipop of P solutions (chromosomes)

Step 2: Calculate all objective functions for each solution in Ipop

Step 3: Specify rank for each solution in Ipop (by non-domination sorting process)

Step 4: Apply the roulette wheel selection based on obtained ranks

Step 5: Apply the crossover scheme on Ipop based on Pc (crossover probability)

Step 6: Apply the mutation scheme on Ipop based on Pm (mutation probability)

Step 7: Acquire new offspring population Opop

Step 8: Combine Ipop and Opop to create a new population Npop

Step 9: Calculate all objective functions for each solution in Npop

Step 10: Specify rank for each solution in Npop (by non-domination sorting process

Step 11: Estimate density for each solution in Npop (by crowding distance calculation

Step 12: Is the stopping criterion met? Yes (go to Step 14) / No (go to Step 13)

Step 13: Create new Ipop based on obtained ranks (highest ranking) and crowding distances (second priority) and go to Step 2

Step 14: Identify solutions in Npop with rank $\leq 1$ as the final non-dominated Pareto set and go to Step 15

Step 15: Terminate the algorithm

Figure 2. The pseudo-code of the NSGA-II.

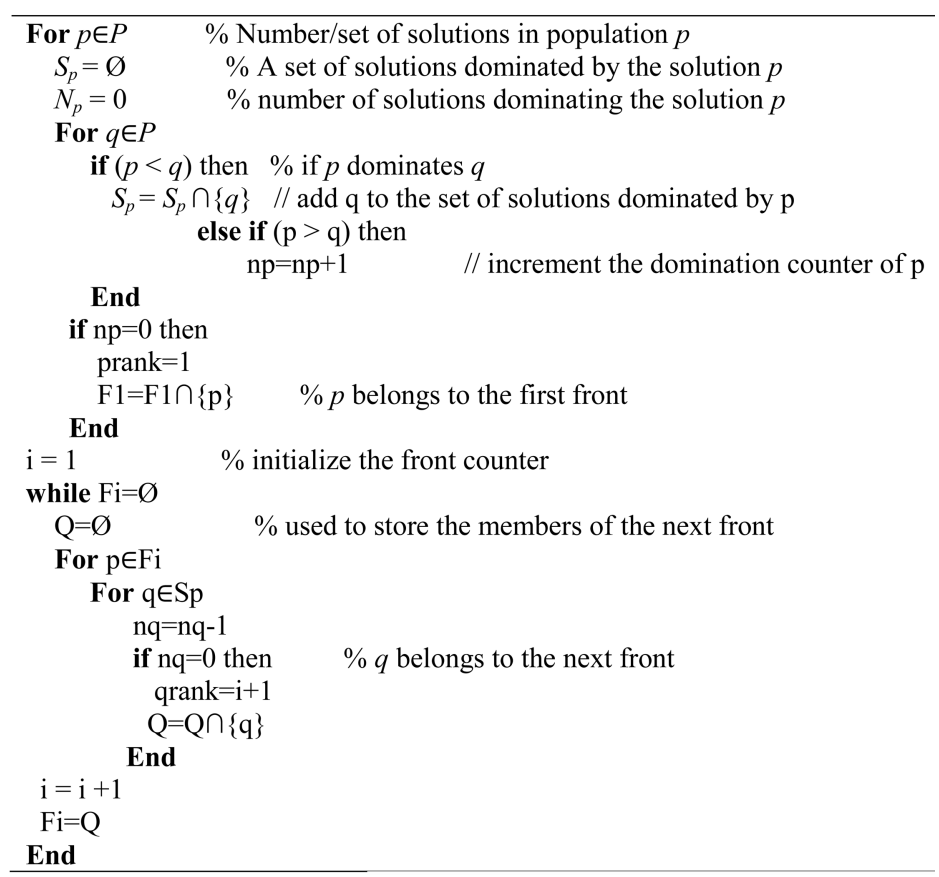

Figure 3. Non-dominated sorting process of NSGA-II.

to select the supplier. Then, in this algorithm, we have a chromosome in the form of a four-dimensional matrix, where the first part is order rate and the second part is selection of suppliers. A chromosome is defined for each product and period, where the genes of this chromosome represent the matrix inputs or the number of suppliers and customers.

\subsubsection{Crossover operator}

In the crossover operator, initial population is con- 


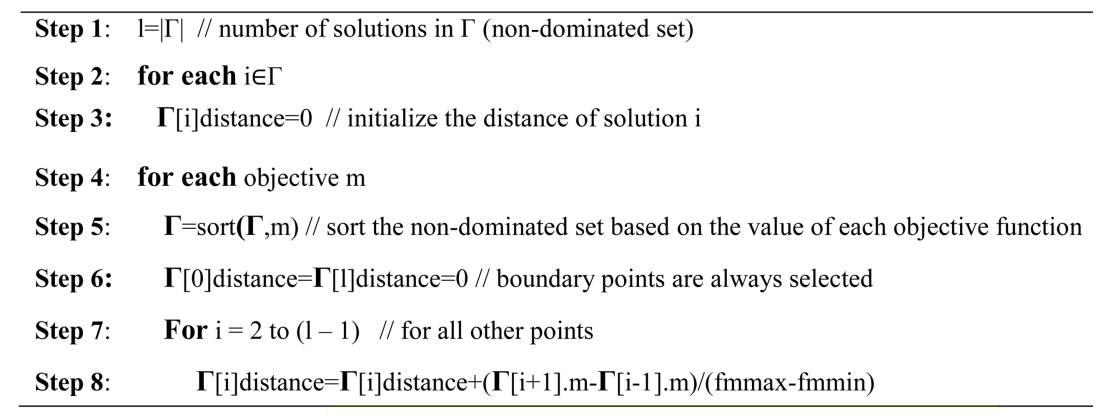

Figure 4. The algorithmic procedure of crowding distance criterion.

structed in a number equal to $n$ crossover; then, selection is performed randomly. In fact, crossover is a function taking the location of two parents and produces two offsprings. In other words, each parent produces two springs. For this operation, the crossover is an arithmetic crossover which is used for a continuous space called continuous crossover operator, according to Coello et al. [43].

\subsubsection{Mutation operator}

In crossover operator, the initial population is generated equal to the number of $n$ mutation. Then, selection is performed randomly. For mutation operator, Gaussian technique in the continuous space is used. So, amount of selected variable $x$ is between $x_{\min }$ and $x_{\max }$ where variable $x$ is converted into $x^{\prime} . \Delta x$ has a normal distribution with mean 0 and variance $\sigma^{2}$ as follows:

$$
\begin{aligned}
& \Delta x \sim N\left(0, \sigma^{2}\right), \\
& x^{\prime}=x+\Delta x \sim N\left(0, \sigma^{2}\right),
\end{aligned}
$$

where $\Delta x$ is defined by a normal distribution function. $\sigma$ is defined as a parameter in the algorithm where we can consider some percent of variables diversity which is $p$ mutation, e.g. 0.1 of difference of upper limit and lower limit of variables:

$$
\sigma=0.1^{*}\left(\operatorname{var}_{\max }-\operatorname{var}_{\min }\right)
$$

To select the number of selected elements or variables, $\alpha$ rate is defined as the mutation rate or effect rate, and it is represented by $\mu$. Parameter percentage of $\mu$ is selected and the operation mentioned in Eq. (22) is applied to the population, based on Coello et al. [43].

\subsubsection{Main operators of NSGA-II}

Even though the sorting process can differentiate between solutions by assigning a rank to each of them with Fast Non-Dominated Sorting (FNDS) operator, there might be some solutions with the same rank by Crowding Distance (CD) operator. CD measures the density of other solutions distributed around a particular solution. The coding process of CD criterion is depicted in Figure 4.

$$
d_{j}(k)=\sum_{\mathbf{i}=\mathbf{1}}^{\mathbf{n}} \frac{f_{i}(k-1)-f_{i}(k+1)}{f_{i}^{\max }-f_{i}^{\min }} .
$$

\subsection{MOPSO}

Particle Swarm Optimization (PSO) was put forward by Eberhart and Kennedy [44]. Particle swarm contains two concepts; one is that the proposed individual will refer to their own experience or experience of others in decision making according to the human decision process. The other is to introduce simple rules to modularize collective natural behavior, according to Boyd and Richerson [45]. In the original PSO, particle $i$ is represented as $X_{i}=\left(X_{i 1}, X_{i 2}, \ldots, X_{i D}\right)$, which accounts for a potential solution to a problem in $D$ dimensional space. Each particle keeps a memory of its previous best position $P_{\text {best }}$ and a velocity along each dimension, represented as $v_{i}=\left(v_{i 1}, v_{i 2}, \ldots, v_{i D}\right)$. At each iteration, the position of the particle with the best fitness value in the search space, designated as $G$, and $P$ vector of the current particle is combined to adjust the velocity along each dimension, and that velocity is then used to compute a new position of the particle. The method could be divided into $G_{\text {Best }}$ and $L_{\text {Best }}$ versions, whose main difference is their definition of the best. In $G_{\text {Best }}$ version, the particle swarm optimizer keeps track of the overall best value, and its location is obtained thus far by any particle in the population, which is called $G_{\text {Best }}$ ( $G$ bestid). For $L_{\text {Best }}$ version, in addition to $g_{B e s t}$, each particle keeps track of the best solution, called $L_{\text {Best }}$ (Lbestid), and it is attained within a local topological neighborhood of particles. However, the particle velocities in each dimension are held to a maximum speed, $v_{\max }$; and the velocity in that dimension is limited to $v_{\max }$, the updating rule is as follows:

$$
\begin{aligned}
\mathbf{V}_{\mathbf{i}, \mathbf{t}}^{\text {new }}= & W \times \mathbf{V}_{\mathbf{i}, \mathbf{t}}^{\text {old }}-1+C_{1} \times \operatorname{rand}_{1} \\
& \times\left(P \text { bestid }-X_{i, t}-1\right)+C_{2} \times \operatorname{rand}_{2} \\
& \times\left(G \text { bestid }-X_{i, t}-1\right),
\end{aligned}
$$




$$
\mathbf{X}_{\mathbf{i}, \mathbf{t}}^{\text {new }}=\mathbf{X}_{\mathbf{i}, \mathbf{t}}^{\text {old }}-1+\mathbf{V}_{\mathbf{i}, \mathbf{t}}^{\text {new }}
$$

where $C_{1}$ and $C_{2}$ determine the relative influence of the social and cognition components (learning factors), while rand $_{1}$ and rand $_{2}$ denote two random numbers uniformly distributed in the interval $[0,1]$. After the first version of PSO was proposed, many efforts have been made to improve the performance of PSO $[46,47]$.

\subsubsection{Main loop of $M O P S O$}

Leader selection is the first step in the major cycle of MOPSO, where a probability distribution is defined. Then, using a rolled cycle, sampling is performed from this probability distribution so as to ascertain what cell to select. Then, a case is selected among the members of this cell. Members of unfitted particles are placed in a repository. In the selection, a cell is selected meeting the competency condition; thus, we have:

$$
n_{i}<n_{j}=>p_{i} \geq p_{j} .
$$

Boltzmann technique is used to define $p$ as:

$$
P_{i} \propto \exp \left(-\beta_{n i}\right) ; \quad p_{i}=\frac{e^{-\beta n i}}{\sum_{j} e^{\beta n j}} .
$$

\subsubsection{Mutation}

Uniform distribution is used to define the mutated particles rate as follows [43]:

$$
P_{m}=\left(1-\frac{i t-1}{\max i t-1}\right)^{5 / \mu},
$$

where $\mu$ is mutation rate to control the plot slope, and it is the number of iteration. As well, to handle the constraints, penalty function is used. If the limit is met, penalty will not be added to penalty amount which is multiplied by a coefficient called alpha and is added to the objective function [35]. Penalty amount in confrontation to various limits is explained in the following equations:

$$
\operatorname{Violation}\left(g \leq g_{0}\right)=\max \left(\frac{g}{g_{0}}-1,0\right)
$$

$$
\begin{aligned}
& \operatorname{Violation}\left(g \geq g_{0}\right)=\max \left(1-\frac{g}{g_{0}}, 0\right), \\
& \operatorname{Violation}\left(g=g_{0}\right)=\left|\frac{g}{g_{0}}-1\right| .
\end{aligned}
$$

Violation objective function is converted into the following equation as follows:

$$
\hat{z}=z+\alpha V \text {. }
$$

\section{Parameters calibration}

Here, Taguchi parameter setting method is applied to three levels of the parameters of the proposed algorithm. The calibration test is performed by Taguchi technique, L27 ( $\left.3^{* *} 5\right)$, i.e. 27 tests are designed from five parameters and three levels are reported in Table 2. Signal-to-Noise (SN) function is also defined as follows:

$$
F(Y)=-10^{*} \log 10\left(\operatorname{Sum}\left(Y^{* *} 2\right) / n\right) .
$$

In this regard, three problems are defined for each suggested test whereby implementing the algorithm for each test; then, the objective function value is computed. Table 3 reports the outputs of these three test problems.

For each test problem, separate objective functions are found. In this part, the mean of each objective function is obtained from three problems. The amount of each objective function obtained for each problem is converted into an objective function through the weighted-sum approach [48]:

$$
\text { Total } Z=w_{1}^{*} Z_{1}+w_{2}^{*} Z_{2}+w_{3}^{*} Z_{3}+w_{4}^{*} Z_{4} \text {. }
$$

Table 3. Generated test problems.

\begin{tabular}{lccc}
\hline \multicolumn{1}{c}{ Problem no. } & $\mathbf{1}$ & $\mathbf{2}$ & $\mathbf{3}$ \\
\hline Number of customer & 5 & 15 & 30 \\
Number of suppliers & 3 & 6 & 10 \\
Number of products & 5 & 10 & 25 \\
Number of period & 2 & 6 & 12 \\
\hline
\end{tabular}

Table 2. The levels defined for parameters of NSGA-II and MOPSO.

\begin{tabular}{llccc}
\hline \multirow{2}{*}{ Algorithm } & \multicolumn{3}{c}{ Parameters } & \multicolumn{3}{c}{ Parameters levels } \\
\cline { 2 - 4 } & & Level & Level 2 & Level 3 \\
\hline \multirow{5}{*}{ NSGA-II } & Maximum number of iterations & 25 & 50 & 100 \\
& Population size & 25 & 50 & 70 \\
& Crossover percentage & 0.5 & 0.7 & 0.9 \\
& Mutation percentage & 0.1 & 0.2 & 0.3 \\
& Mutation rate & 0.01 & 0.03 & 0.05 \\
& & & & \\
\multirow{5}{*}{ MOPSO } & 10 & 15 & 20 \\
& Number of maximum solutions & 50 & 75 & 100 \\
& Population size & 10 & 20 & 30 \\
& Repository size & 0.1 & 0.2 & 0.3 \\
& Mutation percentage & 0.01 & 0.02 & 0.03 \\
\hline
\end{tabular}


Parameter $w$ indicates the weight, or significance functions are of equal importance for decision-makers; $w$ is set to 0.2 . Figures 5 and 6 represent the SN ratio of Taguchi execution for NSGA-II and MOPSO, respectively. The best values of algorithm's parameters determined by Taguchi method are reported in Table 4.

\section{A case study in urban agricultural industry}

These views are, however, inconsistent with informal sector advocates who recognize Urban Agriculture as a form of market rationale-micro entrepreneurship responding to economic incentives in the local economy. Therefore, urban farming is becoming an omnipresent, complex, and dynamic feature of urban landscape and socio-economic reality in Asia, Africa, and Latin America. In the case of this study, the agricultural land of Abhar city in Asia is investigated. This city has an area of 10 square kilometers. There are deep and semi-deep wells where there are 207 deep and semideep wells in this area. The local place of these wells can be observed by the map depicted in Figure 7 . In the case, wells are the suppliers and lands are buyers or customers.

The general data of the case study, including wells location, wells capacity, and related flow, are collected and reported in Table 5 .

The results showed that the objective function

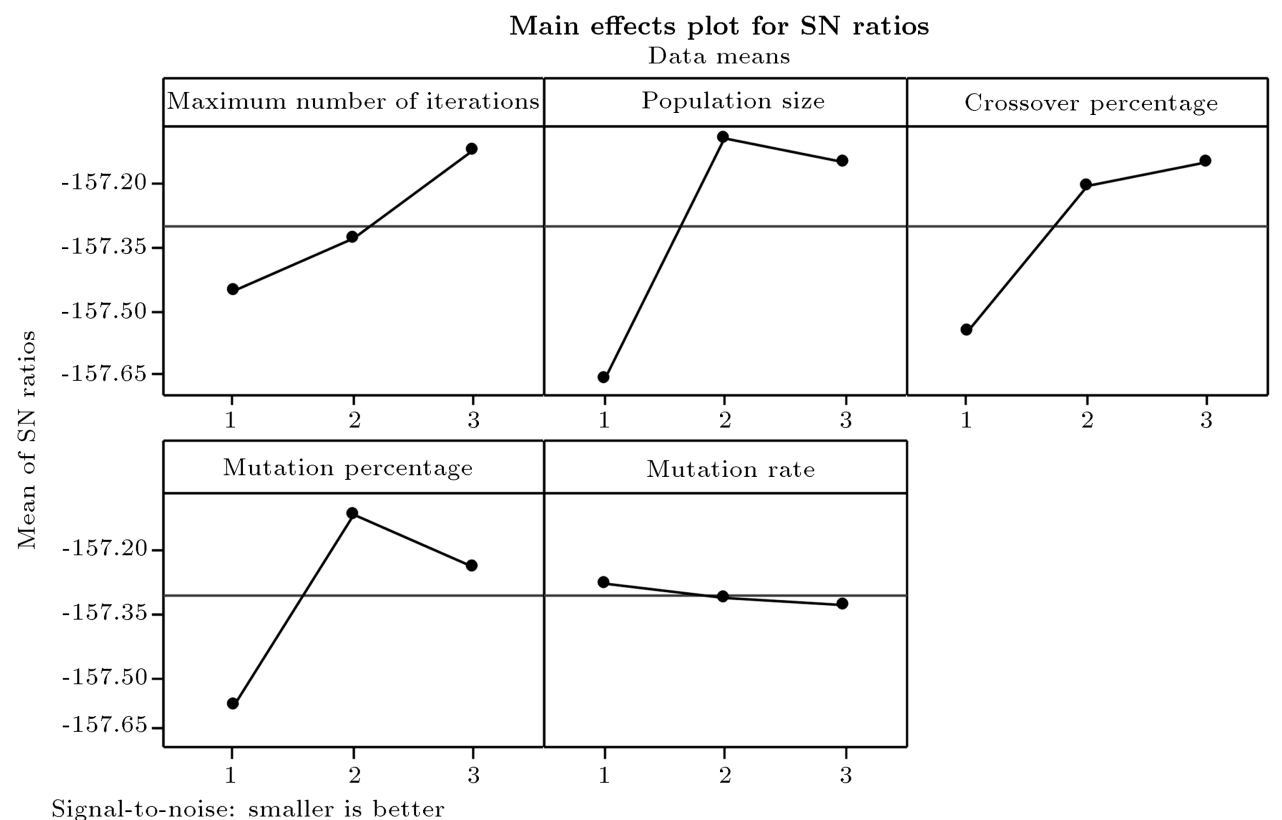

Figure 5. Main effects plot for SN ratios of NSGA-II.

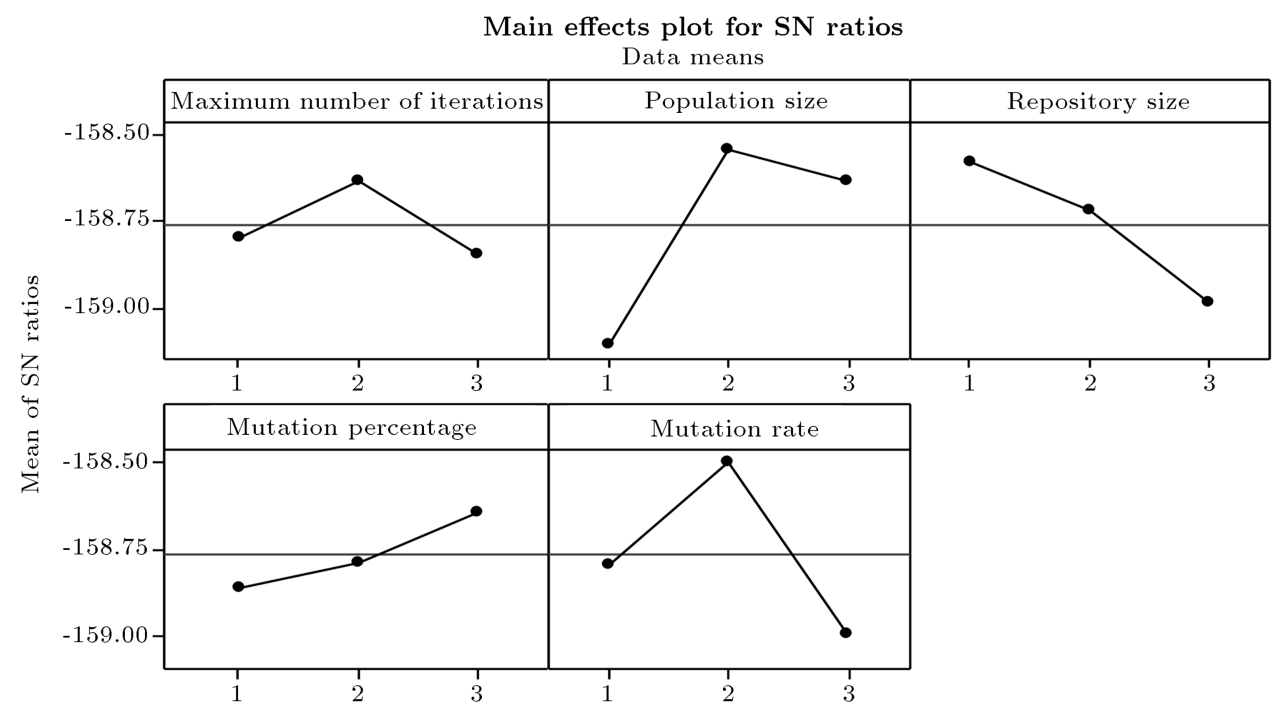

Signal-to-noise: smaller is better

Figure 6. Main effects plot for SN ratio of MOPSO. 
Table 4. The best rations of NSGA-II algorithm parameters.

\begin{tabular}{llc}
\hline Algorithm & \multicolumn{1}{c}{ Parameters } & Optimal value \\
\hline & Maximum number of iterations & 100 \\
NSGA-II & Population size & 50 \\
& Crossover percentage & 0.9 \\
& Mutation percentage & 0.2 \\
& Mutation rate & 0.01 \\
& & \\
& Number of maximum solutions & 15 \\
& Population size & 75 \\
MOPSO & Repository size & 10 \\
& Mutation percentage & 0.3 \\
& Mutation rate & 0.02 \\
\hline
\end{tabular}

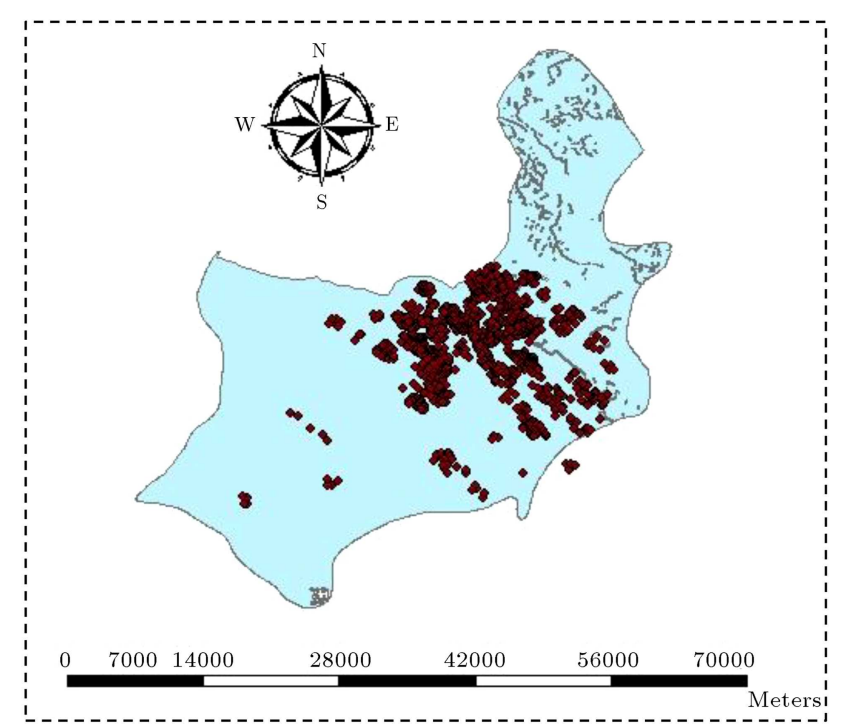

Figure 7. Agricultural irrigated land map of Abhar city.

values, including cost, delay, covering, and weight functions, are based on the investigated case study. Table 6 reports the four objective function values for both MOPSO and NSGA-II.

\section{Results analysis and comparisons}

To evaluate the efficiency and validity of two metaheuristics, six numerical illustrations are considered. Then, ratios of each measure for each function of each sample example are obtained, and finally the mean amount of each measure is defined as the objective function in each sample case. There, we first intro- duce considered performance measures for evaluating and comparing the algorithms; then, the results are analyzed, statistically. Table 7 indicates the input parameters of five test examples.

\subsection{Multi-objective performance metrics}

In order to analyze Pareto solutions in multi-objective optimization, we consider three measures as follows.

\subsubsection{Mean Ideal Distance (MID)}

One of the tests for evaluating the algorithms is the distance from the ideal point. This measure calculates the distance of all points from the best population size. The following equation indicates how to calculate this measure [49]:

$$
\operatorname{MID}=\frac{\sum_{i=1}^{n} c_{i}}{n}
$$

where $c_{i}$ is the distance from the ideal solution $i$, and $n$ is the number of Pareto solutions in the final front.

\subsubsection{Spacing}

By considering spacing measure, the algorithm covers all the solution spaces points. This measure calculates the relative distance of the subsequent solutions. The following solution indicates how to calculate this measure [49]:

$$
S=\sqrt{1 / n \sum_{i=1}^{n}\left(d_{i}-\bar{d}\right)^{2}},
$$

where $\bar{d}=\sum_{i=1}^{n} \frac{d i}{|n|}$ and $d_{i}=\min _{\{k \in N \& k \neq 1\}} \sum_{m=1}^{2}$ $\left|f m^{i}-f m^{k}\right|$. 
Table 5. The general data of wells (suppliers) including the location, capacity, and related flow.

\begin{tabular}{|c|c|c|c|c|}
\hline No. & $X$ coordinate & $Y$ coordinate & Wells (m) & $\begin{array}{c}\text { Permissible } \\
\text { discharge }\end{array}$ \\
\hline 1 & 340008 & 4000513 & 130 & 40 \\
\hline 2 & 342182 & 3997159 & 145 & 50 \\
\hline 3 & 343569 & 3995609 & 70 & 10 \\
\hline 4 & 338030 & 4002761 & 100 & 66 \\
\hline 5 & 341188 & 4006508 & 120 & 20 \\
\hline 6 & 344462 & 3993877 & 150 & 15 \\
\hline 7 & 338973 & 4004133 & 100 & 10 \\
\hline 8 & 336940 & 4002945 & 90 & 50 \\
\hline 9 & 338608 & 4002933 & 100 & 50 \\
\hline 10 & 341885 & 3999106 & 138 & 42 \\
\hline 11 & 339051 & 4004751 & 112 & 25 \\
\hline 12 & 339871 & 4001116 & 130 & 45 \\
\hline 13 & 341810 & 4001767 & 150 & 30 \\
\hline 14 & 342991 & 3996740 & 130 & 37 \\
\hline 15 & 340884 & 3999408 & 120 & 45 \\
\hline 16 & 340390 & 3999854 & 120 & 55 \\
\hline 17 & 340735 & 3998568 & 150 & 37 \\
\hline 18 & 342508 & 3998177 & 140 & 35 \\
\hline 19 & 342430 & 3998916 & 100 & 40 \\
\hline 20 & 341742 & 3999953 & 100 & 35 \\
\hline 21 & 341210 & 4000856 & 70 & 35 \\
\hline 22 & 341632 & 3998004 & 110 & 40 \\
\hline 23 & 342943 & 3997463 & 120 & 35 \\
\hline 24 & 340160 & 4003367 & 105 & 65 \\
\hline 25 & 341460 & 3999052 & 130 & 50 \\
\hline 26 & 343049 & 4003853 & 45 & 25 \\
\hline 27 & 343327 & 4004827 & 100 & 60 \\
\hline 28 & 342872 & 4003050 & 120 & 30 \\
\hline 29 & 342190 & 4002810 & 10 & 10 \\
\hline . & $\cdot$ & $\cdot$ & . & . \\
\hline . & . & . & . & . \\
\hline$\cdot$ & . & . & $\cdot$ & $\cdot$ \\
\hline 335 & 313325 & 4033096 & 127 & 50 \\
\hline 336 & 349593 & 3987906 & 150 & 18 \\
\hline 337 & 344608 & 3993125 & 120 & 30 \\
\hline 338 & 334469 & 4003167 & 155 & 23 \\
\hline 339 & 346850 & 4005716 & 150 & 25 \\
\hline
\end{tabular}

Table 6. The outputs of objective functions values for the case study.

\begin{tabular}{ccccc}
\hline Objective functions & Cost & Delay & Covering & Weight \\
\hline MOPSO & $7.74 \mathrm{E}+11$ & 7863.43 & 3921 & 6449.22 \\
NSGA-II & $6.94 \mathrm{E}+11$ & 8376.82 & 7588 & 7612.81 \\
\hline
\end{tabular}




\subsubsection{Algorithm for solving time}

The final measure is the computational time of algorithm implementation. Algorithms are programmed using MATLAB 7.14.0.739 (R2012a) and implemented on a PC under Windows $7,2.40 \mathrm{GHz}$, RAM 4 GB. Figures 8-10 are the outputs of executing NSGA-II and MOPSO by concentrating on algorithm comparison in terms of MID, spacing, and computational time metrics. Table 8 reports the computational results of both MOPSO and NSGA-II for the generated problems.

\subsection{Statistical analysis comparisons}

For this purpose, one-way variance analysis technique and Minitab are applied. As well, to confirm the parametric results, a non-parametric test called Kruskal Wallis test was used (Montgomery, 2000). If data are suitable for variance analysis, non-parametric test is

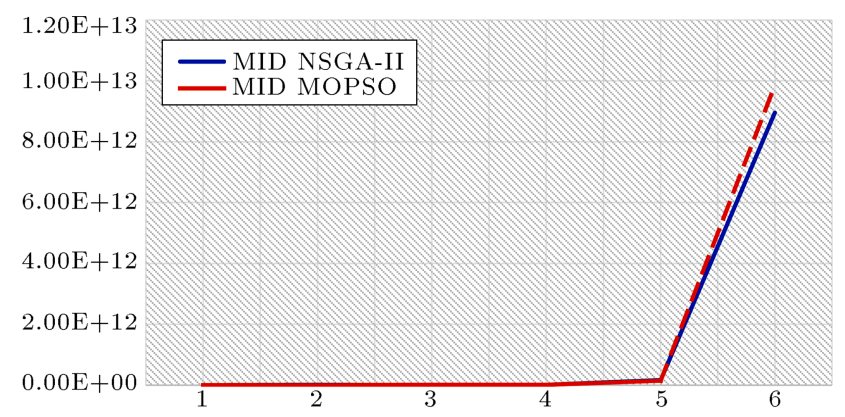

Figure 8. Comparing MOPSO and NSGA-II regarding MID metric.

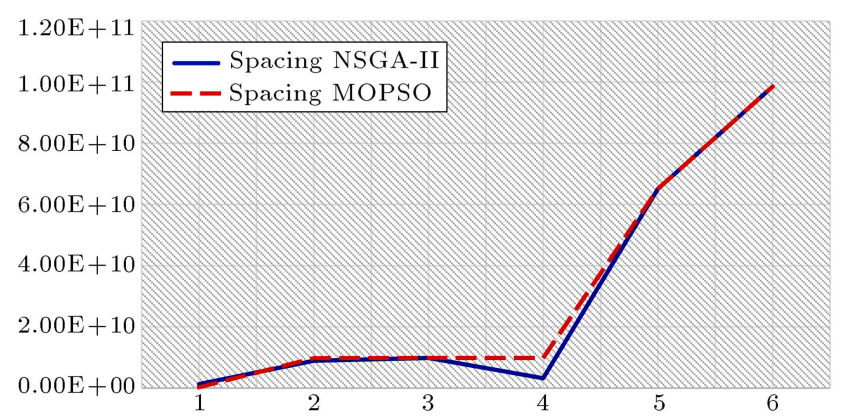

Figure 9. Comparing MOPSO and NSGA-II in terms of metric Spacing.

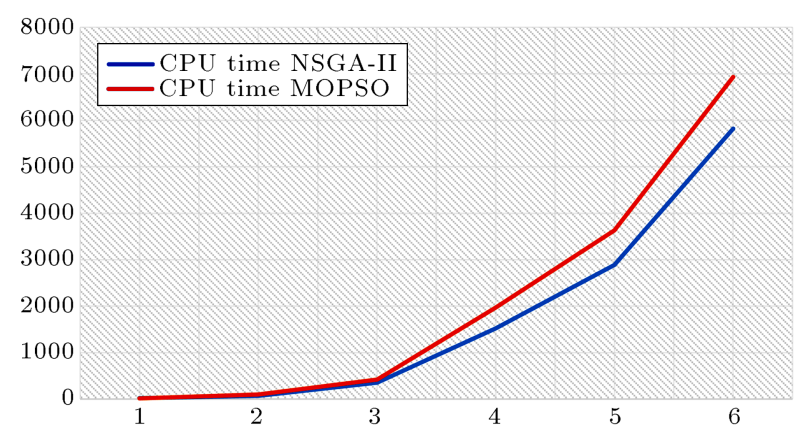

Figure 10. Comparing MOPSO and NSGA-II in terms of computational time metric.
Table 7. Input parameters of five numerical illustrations.

\begin{tabular}{lcccccc}
\hline \multicolumn{1}{c}{ Problem no. } & $\mathbf{1}$ & $\mathbf{2}$ & $\mathbf{3}$ & $\mathbf{4}$ & $\mathbf{5}$ & $\mathbf{6}$ \\
\hline Number of customers & 5 & 10 & 15 & 30 & 50 & 70 \\
Number of suppliers & 3 & 6 & 10 & 15 & 20 & 30 \\
Number of products & 2 & 5 & 10 & 25 & 50 & 100 \\
Number of periods & 2 & 4 & 5 & 6 & 12 & 12 \\
\hline
\end{tabular}

used where there is no precondition for uniformity of the variance or normal distribution. Results of oneway variance analysis and non-parametric test for three measures are provided in Tables 9-14.

For MID metric comparisons, $p$-value of ANOVA test is larger than 0.05. Then, it is concluded that there is no difference between the two algorithms. As observed, $p$-value of Kruskal-Wallis non-parametric test is greater than 0.05 and is equal to 0.749 . Thus, $H_{0}$ is not rejected. Tables 9 and 10 report the mentioned results for MID metric.

For spacing metric comparisons, $p$-value is larger than 0.05. Then, it is concluded that there is no difference between the means of two algorithms. As observed, $p$-value of Kruskal-Wallis non-parametric test is larger than 0.05 and is equal to 0.689. Thus, $H_{0}$ is not rejected. Tables 11 and 12 report the mentioned results for metric spacing.

For computational time metric comparisons, $p$ value is larger than 0.05 . Thus, it is concluded that there is no difference between the means of two algorithms. As well, $p$-value of Kruskal-Wallis nonparametric test is greater than 0.05 and is equal to 0.749. Thus, $H_{0}$ is not rejected. Tables 13 and 14 report the mentioned results of the computational time metric.

The individual-plots of all thee metrics are depicted in Figure 11.

As seen both algorithms work the same on the problem at hand, and it can be the validation of the results in the case study and generated test problems. Graphically, it was concluded that NSGA-II is superior in the measures of CPUT and spacing; however, MOPSO has a better performance in MID metric.

\section{Conclusion and directs for future researches}

In this paper, we presented a fuzzy multi-objective model to select and allocate the orders to suppliers in uncertain conditions, taking into accounts multi-period, multi-source, multi-customer, and multiproduct cases at two levels of supply chain. Deference, coverage, and wastes parameters in this model are considered as uncertain and random triangular fuzzy number. Since the proposed mathematical model is NP-hard, MOPSO and NSGA-II are applied to solve the multi-objective model. In order to demonstrate the 
Table 8. Computational results of MOPSO and NSGA-II for the generated problems.

\begin{tabular}{|c|c|c|c|c|c|c|}
\hline \multirow{2}{*}{$\begin{array}{l}\text { Test problem } \\
\text { no. }\end{array}$} & \multicolumn{2}{|c|}{ MID } & \multicolumn{2}{|c|}{ Spacing } & \multicolumn{2}{|c|}{ CPU time } \\
\hline & MOPSO & NSGA-II & MOPSO & NSGA-II & MOPSO & NSGA-II \\
\hline 1 & 18.55 & 19.85 & $2.65 \mathrm{E}+08$ & $1.31 \mathrm{E}+09$ & $6.55 \mathrm{E}+07$ & $5.91 \mathrm{E}+07$ \\
\hline 2 & 99.65 & 68.55 & $9.70 \mathrm{E}+09$ & $8.95 \mathrm{E}+09$ & $1.63 \mathrm{E}+09$ & $6.99 \mathrm{E}+09$ \\
\hline 3 & 422.21 & 352.55 & $9.84 \mathrm{E}+09$ & $9.84 \mathrm{E}+09$ & $8.79 \mathrm{E}+09$ & $5.42 \mathrm{E}+09$ \\
\hline 4 & 1966.80 & 1523.14 & $9.84 \mathrm{E}+09$ & $3.22 \mathrm{E}+09$ & $9.85 \mathrm{E}+09$ & $6.85 \mathrm{E}+09$ \\
\hline 5 & 3634.19 & 2885.06 & $6.52 \mathrm{E}+10$ & $6.51 \mathrm{E}+10$ & $1.50 \mathrm{E}+11$ & $1.65 \mathrm{E}+11$ \\
\hline 6 & 6932.88 & 5822.67 & $9.85 \mathrm{E}+10$ & $9.85 \mathrm{E}+10$ & $9.85 \mathrm{E}+12$ & $8.95 \mathrm{E}+12$ \\
\hline
\end{tabular}

Table 9. Results of one-way variance analysis for MID metric.

\begin{tabular}{cccccc}
\hline Source & DF & SS & MS & F & $\boldsymbol{p}$-value \\
\hline Solver & 1 & $6.54188 \mathrm{E}+22$ & $6.54188 \mathrm{E}+22$ & 0.00 & 0.948 \\
Error & 10 & $1.46535 \mathrm{E}+26$ & $1.46535 \mathrm{E}+25$ & & \\
Total & 11 & $1.46600 \mathrm{E}+26$ & & & \\
\hline
\end{tabular}

Table 10. Kruskal-Wallis non-parametric test for MID metric.

\begin{tabular}{ccccc}
\hline Solver & $\boldsymbol{N}$ & Median & Rank & $\boldsymbol{Z}$ \\
\hline MOPSO & 6 & 9320000000 & 6.8 & 0.32 \\
NSGA-II & 6 & 6920000000 & 6.2 & -0.32 \\
Overall & 12 & & 6.5 & \\
\hline \multicolumn{7}{c}{$H=0.10$} & DF $=1$ & $p$-value $=0.749$ \\
\hline
\end{tabular}

applicability of the proposed problem, a case study in urban agriculture has been executed. It was concluded that NSGA-II outperforms MOPSO algorithm based on the CPUT and spacing; however, MOPSO has a better performance in MID metric. Statistical and oneway variance analysis and hypothesis testing show that both algorithms are relatively equal, and the results of two algorithms do not differ significantly; implementing the non-parametric test indicates the accuracy of this claim. Also, we conclude that NSGA-II and MOPSO are capable of finding and managing Pareto solutions for the proposed model. However, it is valuable to consider that if the time and spacing are important for decision-makers, NSGA-II can be a better choice, while, in MID desire, MOPSO algorithm is better
Table 12. Kruskal-Wallis non-parametric test for metric Spacing.

\begin{tabular}{ccccc}
\hline Solver & $\boldsymbol{N}$ & Median & Rank & $\boldsymbol{Z}$ \\
\hline MOPSO & 6 & 9840000000 & 6.9 & 0.40 \\
NSGA-II & 6 & 9395000000 & 6.1 & -0.41 \\
Overall & 12 & & 6.5 & \\
\hline \multicolumn{3}{c}{$H=0.16$} & DF $=1$ & $p$-value $=0.689$ \\
\hline
\end{tabular}

Table 13. Results of one-way variance analysis for computational time metric.

\begin{tabular}{cccccc}
\hline Source & DF & SS & MS & $\boldsymbol{F}$ & $\boldsymbol{p}$-value \\
\hline Solver & 1 & 480985 & 480985 & 0.08 & 0.787 \\
Error & 10 & 62534640 & 6253464 & & \\
Total & 11 & 63015625 & & & \\
\hline
\end{tabular}

Table 14. Kruskal-Wallis non-parametric test for computational time metric.

\begin{tabular}{ccccc}
\hline Solver & $\boldsymbol{N}$ & Median & Rank & $\boldsymbol{Z}$ \\
\hline MOPSO & 6 & 1194.5 & 6.8 & 0.32 \\
NSGA-II & 6 & 937.8 & 6.2 & -0.32 \\
Overall & 12 & \multicolumn{3}{c}{6.5} \\
\hline \multicolumn{3}{c}{$H=0.10$} & DF $=1$ & $p$-value $=0.749$ \\
\hline
\end{tabular}

Table 11. Results of one-way variance analysis for metric spacing.

\begin{tabular}{cccccc}
\hline Source & DF & SS & MS & $\boldsymbol{F}$ & $\boldsymbol{p}$-value \\
\hline Solver & 1 & $3.44005 \mathrm{E}+18$ & $3.44005 \mathrm{E}+18$ & 0.00 & 0.964 \\
Error & 10 & $1.63168 \mathrm{E}+22$ & $1.63168 \mathrm{E}+21$ & & \\
Total & 11 & $1.63203 \mathrm{E}+22$ & & & \\
\hline
\end{tabular}




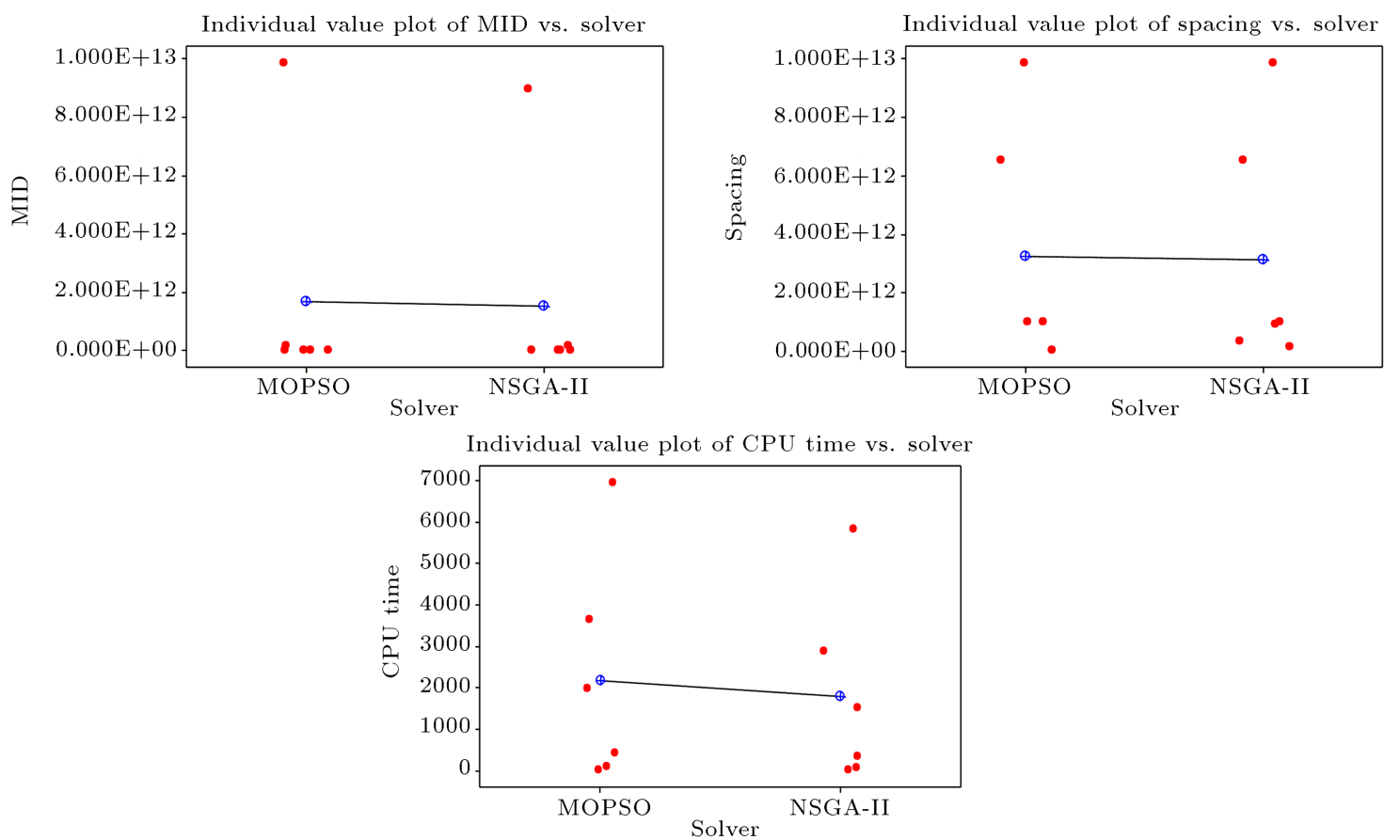

Figure 11. Individual value plot of MID, Spacing, and CPU time.

one. In the case of the future trend, we can suggest that more appropriate versions of other multi-objective algorithms are used. Besides, other objectives and constraints, such as waste, risk, and disruption, can be added to the problem to develop the model in fuzzy environment.

\section{References}

1. Simchi-Levi, D., Kaminsky, P. and Simchi-Levi, E., Designing and Managing the Supply Chain, 2nd Ed., Boston: Irwin McGraw-Hill (2003).

2. Ghiani, G., Laporte, G. and Musmanno, R., Introduction To Logistics Systems Planning and Control, John Wiley \& Sons, Inc., Hoboken, New Jersey (2004).

3. Dulmin, R. and Mininno, V. "Supplier selection using a multi-criteria decision aid method", Journal of Purchasing and Supply Management, 9, pp. 177-187 (2003).

4. Hugos, M.E., Essentials of Supply chain Management, 2nd Ed. New Jersey: Wiley (2006).

5. Karasakal, O. and Karasakal, E. "A maximal covering location model in the presence of partial coverage", Computers \& Operations Research, 31(9), pp. 15151526 (2004).

6. Liang, T. "Fuzzy multi-objective production/distribution planning decisions with multi-product", Computers \& Industrial Engineering, 55(3), pp. 676-694 (2008).

7. Torabi, S. and Hassini, E. "Multi-site production planning integrating procurement and distribution plans in multi-echelon supply chains: An interactive fuzzy goal programming approach", International Journal of Production Research, 159, pp. 193-214 (2008).

8. Fatih, E., Serkan, G., Mustafa, K. and Diyar, A. "A multi-criteria intuitionistic fuzzy group decision making for supplier selection with TOPSIS method", Expert Systems With Applications, 36(8), pp. 1136311368 (2009).

9. Onot, S., Selin, S. and Işik, E. "Long term supplier selection using a combined fuzzy MCDM approach: A case study for a telecommunication company", Expert Systems With Applications, 36(2), pp. 38873895 (2009).

10. Amid, A., Ghodsypour, S. and O'Brien, C. "A weighted additive fuzzy multi objective model for the supplier Selection problem under price breaks in a supply chain", International Journal Production Economics, $131(1)$, pp. 323-332 (2009).

11. Kokangol, A. and Susuz, Z. "Integrated analytical hierarch process and mathematical programming to supplier selection problem with quantity discount", Applied Mathematical Modeling, 33(3), pp. 1417-1420 (2009).

12. Tsai, W. and Wang, C. "Decision making of sourcing and order allocation with price discounts", Journal of Manufacturing Systems, 29, pp. 47-54 (2010).

13. Atakhan, Y. and Ali Fuat, G. "A weighted additive fuzzy programming approach for multi-criteria supplier selection", Expert Systems With Applications, 38(5), pp. 6281-6286 (2011).

14. Haleh, H. and Hamidi, A. " A fuzzy MCDM model for allocating orders to suppliers in a supply chain under uncertainty over a multi-period time horizon", 
Expert Systems With Applications, 38(8), pp. 90769083 (2011).

15. Liao, S.H., Lin, H. and Lai, P. "An evolutionary approach for multi-objective optimization of the integrated location-inventory distribution network problem in vendor-managed inventory", Expert Systems With Applications, 38(6), pp. 6768-6776 (2011).

16. Lin, H. " An integrated model for supplier selection under a fuzzy situation", International Journal Production Economics, 138, pp. 55-61 (2012).

17. Shaw, K., Shankar, R., Yadav, S. and Thakur, L. "Supplier selection using fuzzy AHP and fuzzy multiobjective linear programming for developing low carbon supply chain", Expert System With Applications, 39, pp. 8182-8192 (2012).

18. Nazari Shirkouhi, S., Shakouri, H., Javadi, B. and Keramati, A. "Supplier selection and order allocation problem using a two-phase fuzzy multi-objective linear programming", Applied Mathematical Modelling, 37, pp. 9308-9323 (2013).

19. Esfandiari, N. and Seifbarghy, M. "Modeling a stochastic multi-objective supplier quota allocation problem with price-dependent ordering", Applied Mathematical Modelling, 37(8), pp. 5790-5800 (2013).

20. Arikan, F. "A fuzzy solution approach for multi objective supplier selection", Expert Systems With Applications, 40(3), pp. 947-952 (2013).

21. Meena, P. and Sarmah, S. "Multiple sourcing under supplier failure risk and quantity discount: A genetic algorithm approach", Transportation Research Part E, 50, pp. 84-97 (2013).

22. Hajipour, V., Khodakarami, V. and Tavana, M. "The redundancy queuing-location-allocation problem: A novel approach", IEEE Transactions on Engineering Management, 61(3), pp. 534-544 (2014a).

23. Hajipour, V., Rahmati, S.H.A., Pasandideh, S.H.R. and Niaki, S.T.A. "A multi-objective harmony search algorithm to optimize multi-server location-allocation problem in congested systems", Computers \& Industrial Engineering, 72, pp. 187-197 (2014b).

24. Patra, K. and Kumar Mondal, S. "Multi-item supplier selection model with fuzzy risk analysis studied by possibility and necessity constraints", Fuzzy Information and Engineering, 7(4), pp. 451-474 (2015).

25. Orji, I.J. and Wei, S. "An innovative integration of fuzzy-logic and systems dynamics in sustainable supplier selection: A case on manufacturing industry", Computers \& Industrial Engineering, 88, pp. 1-12 (2015).

26. Rahiminezhad Galankashi, M., Helmi, S.A. and Hashemzahi, P. "Supplier selection in automobile industry: A mixed balanced scorecard-fuzzy AHP approach", Alexandria Engineering Journal, In press (2016). DOI: 10.1016/j.aej..01.005

27. Amorim, P., Curcio, E., Almada-Lobo, B., BarbosaPóvoa, A.P., and Grossmann, I.E. "Supplier selection in the processed food industry under uncertainty", European Journal of Operational Research, 252(3), pp. 801-814 (2016).

28. Çebi, F. and Otay, I. "A two-stage fuzzy approach for supplier evaluation and order allocation problem with quantity discounts and lead time", Information Sciences, 339(20), pp. 143-157 (2016).

29. Niaki, S.T.A., Taleizadeh, A. and Barzinpour, F. "Multiple-buyer multiple-vendor multi-product multiconstraint supply chain problem with stochastic demand and variable lead-time", Applied Mathematics and Computation, 217, pp. 9234-9253 (2011).

30. Jiuping, Xu, Qiang, Liu, Rui Wang. "A class of multi-objective supply chain networks optimal model under random fuzzy environment and its application to the industry of Chinese liquor", Information Sciences, 178, pp. 2022-2043 (2008).

31. Kamran, S. and Moghaddam, K.S. "Fuzzy multiobjective model for supplier selection and order allocation in reverse logistics systems under supply and demand uncertainty", Expert Systems with Applications, 42(15-16), pp. 6237-6254 (2015).

32. Sodenkamp, M.A., Tavana, M. and Di Caprio, D. "Modeling synergies in multi-criteria supplier selection and order allocation: An application to commodity trading", European Journal of Operational Research, 254(3), pp. 859-874 (2016)

33. Mei, Y., Salim, F.D. and Li, X. "Efficient metaheuristics for the multi-objective time-dependent orienteering problem", European Journal of Operational Research, 254(2), pp. 443-457 (2016).

34. Ozcan-Deniz, G. and Zhu, Y. "Multi-objective optimization of greenhouse gas emissions in highway construction projects", Sustainable Cities and Society, 28, pp. 162-171 (2017).

35. Hussain, M., Khan, M. and Al-Aomar, R. "A framework for supply chain sustainability in service industry with confirmatory factor analysis", Renewable and Sustainable Energy Reviews, 55, pp. 1301-1312 (2016).

36. Sadeghi, J., Mousavi, S.M., Niaki, S.T.A. and Sadeghi, S. "Optimizing a multi-vendor multi-retailer vendor managed inventory problem: Two tuned metaheuristic algorithms", Knowledge-Based Systems, 50, pp. $159-170$ (2013).

37. Lu, J., Han, J., Hu, Y. and Zhang, G. "Multilevel decision-making: A survey", Information Sciences, 346, pp. 463-487 (2016).

38. Lemmens, S., Decouttere, C., Vandaele, N. and Bernuzzi, M. "A review of integrated supply chain network design models: Key issues for vaccine supply chains", Chemical Engineering Research and Design, 109, pp. 366-384 (2016).

39. Zadeh, L. "Fuzzy set as a basis for a theory of possibility", Fuzzy Sets and Systems, 1, pp. 3-28 (1978).

40. Chen, C. " Extensions of TOPSIS for group decision making under fuzzy environment", Fuzzy Set and System, 114, pp. 1-9 (2000). 
41. Ross, T.J., Fuzzy Logic with Engineering Applications, John Willey \& Sons (2005).

42. Deb, K., Pratap, A., Agarwal, S. and Meyarivan, T.A.M.T. "A fast and elitist multiobjective genetic algorithm: NSGA-II", IEEE Transactions on Evolutionary Computation, 6(2), pp. 182-197 (2002).

43. Coello Coello, Carlos, Lamont, Gary B., van Veldhuizen, David A., Evolutionary Algorithms for Solving Multi-Objective Problems, New York: Kluwer Academic Publishers (2002).

44. Eberhart, R. and Kennedy, J. "A new optimizer using particle swarm theory", In Proceedings of the Sixth International Symposium on Micro and Machine and Human Science, 47, pp. 39-43 (1995).

45. Boyd, R. and Richerson, P.J., Culture and the Evolutionary Process, University of Chicago Press, Chicago (1985).

46. Boeringer, D.W. and Werner, D.H. "Particle swarm optimization versus genetic algorithms for phased array synthesis", IEEE Trans. Antennas Propag., pp. 771-779 (2004).

47. Hajipour, V. and Pasandideh, S.H.R. " Proposing an adaptive particle swarm optimization for a novel biobjective queuing facility location model", Economic Computation and Economic Cybernetics Studies and Research, 47(3), pp. 112-129 (2012).

48. Szidarovszky, F., Gersbon, M.E. and Duckstein, L., Techniques for Multiobjective Decision Making in Systems Management, Elsevier Publishers B.V. (1985).
49. Boloori Arabani, A., Zandieh, M. and Fatemi Ghomi, S. "Multi-objective genetic-based algorithms for a cross-docking scheduling problem", Applied Soft Computing, pp. 4954-4970 (2011).

\section{Biographies}

Alborz Hajikhani is a PhD student in the Department of Industrial Engineering at the Science and Research Branch of Islamic Azad University, Tehran, Iran. His areas of interest include fuzzy logic, multicriteria decision making, and supply chain management.

Mohammad Khalilzadeh received his Ms and $\mathrm{PhD}$ degrees in Industrial Engineering from Sharif University of Technology, Tehran, Iran. He is currently an Associate Professor in the Industrial Engineering Department of the Science and Research Branch of the Islamic Azad University, Tehran, Iran. His research interests are in project management, fuzzy multiplecriteria decision making, and system thinking.

Seyed Jafar Sadjadi graduated from Iran University of Science and Technology in Industrial Engineering and finished his $\mathrm{PhD}$ graduate studies in the University of Waterloo, Ontario, Canada. His area of research is more on optimization problems and supply chain planning. 